\title{
Leirner, P. de C. (2020). O Brasil no Espectro de uma Guerra Hibrida: militares, operações psicológicas e política em uma perspectiva etnográfica. São Paulo: Alameda Editorial. 329 p.
}

\author{
CIMÉA BARBATO BEVILAQUA \\ UNIVERSIDADE FEDERAL DO PARANÁ (UFPR), CURITIBA/PR, BRASIL \\ HTTPS://ORCID.ORG/OOOO-0002-6886-0395
}

A forma mais simples de apreciar a importância da obra de Piero Leirner está em seu próprio título: não é todos os dias que um vocabulário analítico especializado é incorporado ao debate público sobre os impasses da vida nacional. A repercussão do léxico associado à guerra híbrida, disseminado a partir da análise de Leirner, deve-se sem dúvida ao seu poder de elucidar os sobressaltos políticos e as transformações do Estado em curso no Brasil. Todavia, a conjuntura é apenas a camada mais evidente de um movimento analítico que se desenvolve simultaneamente em diferentes escalas e dimensões - e, nesse sentido, é isomórfico ao seu objeto.

Versão pouco modificada da tese de professor titular de Antropologia do autor, defendida em dezembro de 2019 na Universidade Federal de São Carlos, o livro desenvolve uma reflexão teórica profundamente original, lastreada em uma trajetória de pesquisa com militares que remonta à década de 1990 - e, no período mais recente, em um percurso etnográfico singular, que radicaliza o caráter relacional do conhecimento antropológico e dá nova expressão a uma antropologia pública. É também uma contribuição para a história da disciplina, não simplesmente por retraçar antigas e sempre controversas relações entre antropólogos e forças armadas, mas ao expor a perturbadora conversão de conhecimento antropológico em doutrina militar. Se esse movimento passa a prescindir da participação direta de profissionais da área, sua origem é precisamente o que permite ao antropólogo compreendê-lo de forma mais acurada.

Como o autor narra na introdução, a percepção de que processos em curso no Brasil evocavam elementos de sua experiência de pesquisa começou a se delinear em 2014. Ao ver pela primeira vez a expressão "guerra híbrida" ser empregada por um antigo interlocutor, a intuição ganhou contornos mais nítidos: as chamadas "jornadas de junho" de 2013 tinham muitas similaridades com o que ora é reconhecido como uma estratégia norte-americana para provocar "revoluções coloridas" e desestabilizar governos, ora identificado como uma doutrina conspiratória russa com sinal invertido e fins 
similares - como sustentavam as publicações dirigidas ao público militar brasileiro que começavam a se multiplicar.

Nestas, uma combinação peculiar de diferentes elementos de teorias da guerra híbrida, amalgamados a preocupações e diretrizes preexistentes nas Forças Armadas, disseminava a ideia de que o Brasil estava sob ataque e localizava o inimigo não apenas no interior das nossas fronteiras, mas no coração do próprio governo. Simultaneamente, a Operação Lava-Jato produzia seus primeiros efeitos e consagrava os heróis da mais recente cruzada anticorrupção.

Acredito que Leirner tenha percebido antes que qualquer um de nós o padrão inusual que conectava essas iniciativas: não apenas a ação disruptiva de setores do Estado contra outros setores do Estado, mas a projeção de seus próprios movimentos como ações daqueles contra os quais se dirigiam. Esses indícios o levaram a retomar elementos sedimentados ao longo de sua trajetória de pesquisa, ao mesmo tempo em que se engajava na discussão política em tempo real com um espectro crescente de interlocutores. O que de início foi uma reação ao enredo político-jurídico corrosivo que se precipitava, e um esforço para compreender o papel que nele cabia às Forças Armadas, tornou-se um experimento etnográfico de produção de conhecimento em rede, em especial via Facebook, "em um ciclo de alimentação e feedback" (:45). E não por acaso.

Em virtude de suas qualidades homólogas, faz parte da doutrina da guerra híbrida a percepção das redes sociais como equivalente bélico do "terreno" nas guerras clássicas. Neste caso, portanto, entrar nas redes sociais e agir nelas equivalia ao preceito antropológico clássico de "entrar em campo" e participar de uma das frentes em que a guerra é travada (:46). Desencadeou-se assim um esforço cotidiano de análise pela experimentação com noções militares associadas à guerra híbrida, em especial a de "operações psicológicas". Suas múltiplas refrações deram origem à tese agora transformada em livro, cujo registro de escrita, quase coloquial, guarda as marcas da própria situação etnográfica. Publicações no Facebook, entrevistas, notícias, trabalhos acadêmicos, documentos e manuais militares reagem uns aos outros "sem distinção, sem hierarquização: em rede" (:54).

A proposição de base, desenvolvida ao longo de três capítulos, é a da existência de uma guerra híbrida em curso no Brasil, operada em várias escalas e há muito mais tempo do que se imagina. A chegada de Jair Bolsonaro à presidência é um de seus efeitos, mas seguramente não o último: a guerra híbrida não tem como horizonte o seu próprio fim. Por isso mesmo, a conclusão do volume não é um epílogo, mas a transição para um novo estágio, paradoxal apenas se lido a partir da oposição canônica entre política e guerra: o governo da guerra hibrida, cujas contradições fabricadas camuflam uma completa reconfiguração do Estado e a concentração de seus poderes no que Leirner designa como um "consórcio militar".

De acordo com o autor, o que distingue o caso brasileiro é um percurso inverso ao dos ataques híbridos que desencadeiam revoluções coloridas, nos quais o agenciamento de protestos nas ruas avança Estado adentro, solapando suas estruturas. Aqui, uma doutrina da guerra híbrida gestada no núcleo militar teria operado inicialmente no interior das próprias Forças Armadas, muito antes de se estender para além da caserna. Seus mecanismos entram gradualmente em ressonância com outros atores e instituições - notadamente o judiciário, mas também seus próprios alvos -, até que a guerra híbrida se 
torne "um fenômeno estrutural e disseminado" (:282). É preciso não perder de vista que a produção do conceito é, de saída, sua própria efetivação e o influxo de seu alastramento, de forma tão mais eficaz quanto mais imperceptível para os agentes que participam dessa dinâmica. Como insiste o autor, trata-se efetivamente de "uma dinâmica de guerra, não de uma maquinação militar sem maiores efeitos" (:43).

A essa altura, deve estar claro que o escopo da análise não é a "aplicação" da (ou de uma) noção de guerra híbrida como uma fórmula para o entendimento da história brasileira recente, mas a apreensão etnográfica de agenciamentos "nativos" (embora não inteiramente autóctones), amadurecida ao longo de um percurso intelectual que vai da política à guerra e desta retorna à política (:58).

No capítulo 1, Leirner remonta aos primeiros passos de sua experiência de mais de 25 anos de pesquisa com militares. Se a noção de guerra híbrida implica a dissolução da fronteira entre política e guerra, no Brasil do início dos anos de 1990 se tratava justamente de reinstaurar a separação entre ambas, depois de duas décadas de regime militar. Prevalecia então nas ciências sociais um firme consenso segundo o qual a intervenção fardada na vida pública advinha de alguma "falha" ou "anomalia" na política. Considerando, entretanto, o número e a distribuição global de golpes de Estado envolvendo militares na história recente, era o próprio consenso analítico que suscitava interrogação (:58-61).

Delineia-se assim um projeto radicalmente inovador: tomar a guerra como ponto de partida para compreender a movimentação política de militares. Num primeiro momento, esse percurso leva a interpelar uma longa tradição intelectual que toma as fronteiras entre o público e o doméstico, a política e a guerra como premissas não-problemáticas. A agudização recente das qualidades híbridas da guerra, por sua vez, permite reequacionar o entendimento de suas relações com a política e a própria noção de intervenção militar. Encontra-se aí o cerne do argumento teórico do livro, mas chegar a ele requer, por assim dizer, aproximações sucessivas em diferentes planos.

O primeiro deles é uma experiência etnográfica marcada pela constante produção de ambiguidades e contradições. Não se trata de um detalhe trivial: tal padrão faz parte dos manuais militares de “operações psicológicas”, cuja importância cresce no Brasil a partir de fins da década de 1990, reverberando o rearranjo das concepçóes da guerra na doutrina norte-americana a partir da "captura da antropologia pela máquina de guerra” (:85).

Para o entendimento desse processo, Leirner recupera parte da história das relações entre a antropologia e as forças armadas, em especial a participação de antropólogos britânicos e norte-americanos na Segunda Guerra. Particularmente decisivo, aqui, é o caso de Gregory Bateson. Ainda que à revelia dele mesmo, algumas de suas formulações - notadamente as que decorrem do conceito de cismogênese e de aproximaçóes à cibernética - vieram a ser empregadas em experimentos da inteligência militar norte-americana. Posteriormente, já como parte de um repertório institucional, converteram-se em fundamentos das teorias das guerras irregulares, não convencionais ou híbridas, cujo desenvolvimento prático ocorreria inicialmente em operações no Iraque e no Afeganistão. A expertise adquirida por oficiais brasileiros em treinamentos nos Estados Unidos, infundida por aclimatações doutrinárias locais, teria produzido aquilo a que Leirner se refere como a "virada ontológica" que desaguou na noção (e na prática) da guerra híbrida entre nós. 
Em outro plano e como corolário de um longo acúmulo etnográfico e reflexivo, o capítulo 2 explora teoricamente as condições de emergência dessa nova equação militar. Ou talvez seja mais correto dizer o contrário: são as novas condições da guerra que implicam um reequacionamento da teoria política. $\mathrm{O}$ argumento se desdobra em dois passos. Primeiramente, trata-se não apenas de problematizar a indexação da guerra e da política à gênese do Estado, mas sua persistência como uma espécie de matriz do pensamento que, a despeito da diversidade de suas expressões, replica incessantemente a ideia de que o Estado domestica a guerra e, a partir disso, dispóe política e guerra em campos opostos. Mas se é preciso reafirmar a cada momento essa separação, pergunta Leirner, não seria porque ela própria é em alguma medida artificial e deixa como resíduo inexplicado "a permanência da guerra em um estado latente"? (:127).

Destacar-se da circularidade desse pensamento permite sustentar, num segundo momento, que as situações em que a guerra supostamente "invade" a política não ocorrem em virtude de alguma anomalia desta, mas porque ambas estão constitutivamente imbricadas. Isto requer uma teorização radicalmente diferente, advinda de formas de socialidade que também o são. Se há uma razão, por assim dizer, metodológica para esse passo, conforme a conhecida advertência de Bourdieu sobre os riscos de descrever o Estado e os fenômenos que lhe são (supostamente) correlatos a partir de suas próprias categorias, há também uma motivação etnográfica. Para o coronel Frank Hoffman, tido como o autor da expressão guerra híbrida, alguns de seus componentes evocariam as "guerras primitivas". Contudo, enquanto o militar norte-americano pretendia ressaltar uma suposta ausência de regras, relevante para Leirner é sua indiferença à separação entre domínios ou “esferas”. Assim, a partir de desdobramentos da reflexão antropológica sobre guerras não-estatais, torna-se possível perguntar: se "a guerra híbrida está se tornando uma espécie de 'condição final' da guerra, não será justamente por reproduzir sua característica mais prístina, que é o hibridismo?” (:156).

Para leitoras/es mais interessadas/os na crônica do presente, a importância desse verdadeiro tour de force histórico e teórico pode passar despercebida. Entretanto, é da possibilidade de situar a análise em um ponto (logicamente) anterior às divisões consagradas por nossas teorias políticas que depende a compreensão do alcance mais profundo de métodos e dispositivos bélicos constitutivamente híbridos. Pois ao embaralhar aquilo que foi separado, dissimula-se a própria existência de uma guerra. E menos ainda é possível discernir de onde, afinal, vem o ataque. A demonstração empírica de como essa "grande inversão" tem ocorrido no caso brasileiro, a partir da mobilização analítica, em modo reverso, do próprio repertório que a produz, é a matéria do capítulo 3.

Conforme Leirner destaca, o conceito de cismogênese "está para teoria da guerra híbrida assim como a prática da guerra híbrida induz à cismogênese” (:179). Como já ensinava Bateson, a cismogênese é uma dinâmica relacional que se instaura a partir de aspectos preexistentes e é retroalimentada pelas iniciativas de atores distintos. Desse modo, compreender como militares brasileiros se envolveram na guerra híbrida implica, em primeiro lugar, reter um dado etnográfico fundamental: o modo como o conhecimento é produzido nas Forças Armadas, que favorece sua concentração nas mãos de agentes-chave e se dissemina como instrução. Não menos importante, o imperativo de transformar o pensamento 
em ação alinha em relação especular a descrição do inimigo e o modo como o próprio Exército deve se organizar e agir para enfrentá-lo (:187).

A partir daí Leirner explicita como elementos ideológicos e doutrinários foram articulados por certo núcleo militar na produção de uma teoria da guerra híbrida - cuja propagação na própria caserna, de acordo com o autor, foi também sua primeira atualização. A receita envolve, entre muitos outros ingredientes, o anticomunismo latente desde a Intentona de 1935 e transformações da doutrina da guerra revolucionária que, a partir da década de 1990, acionaram a Amazônia como cenário prototípico. Mais recentemente, a operação no Haiti não apenas acelera a incorporação de um aparato doutrinário e operacional norte-americano, como também propicia uma experiência-laboratório de dissolução da fronteira entre intervenção militar, produção do Estado e exercício do governo. No âmbito interno, a instauração da Comissão da Verdade acirra as tensões entre governo e Forças Armadas e estimula a abertura dos quartéis à política. Paralelamente, a articulação de ações conjuntas com outros agentes institucionais (membros da Polícia Federal, Procuradores e Juízes) aprofunda a indistinção entre defesa e segurança. Por fim, o próprio governo de Dilma Rousseff estabelece o arcabouço político-legal que, com o concurso de inúmeros atores, daria impulso a um novo projeto militar de aparelhamento do Estado e de construção de hegemonia - precisamente aquilo que se atribuiu ao PT.

Conectando com brilhante precisão uma imensa massa de dados, Leirner identifica os princípios, os principais artífices e o passo-a-passo da guerra híbrida brasileira. O impeachment e o lawfare, assim como as eleições de 2018 e as aparentes contradições do atual governo podem então ser vistos como momentos de uma mesma dinâmica de "abordagem indireta" e "criptografia", da qual as Forças Armadas emergem como solução de ordem. Ao expor com refinamento etnográfico, originalidade teórica e uma boa dose de coragem a urdidura dos processos que recolocaram os militares no "centro" da vida nacional, O Brasil no espectro de uma guerra híbrida já nasce como referência incontornável para as ciências sociais. Mais que isso, é leitura urgente para a desarticulação do "domínio de espectro total" prestes a se completar.

\section{Ciméa Barbato Bevilaqua é Doutora em Ciências Sociais (Antropologia Social) pela Universidade de São Paulo (USP) e Professora Titular da Universidade Federal do Paraná (UFPR).}

RECEBIDO: $30 / 12 / 2020$

APROVADO: $20 / 01 / 2021$ 